\title{
Leishmania amazonensis: Characterization of an ecto-3'-nucleotidase activity and its possible role in virulence
}

\author{
Rafael Paletta-Silva ${ }^{a, b}$, Danielle P. Vieira ${ }^{a, c}$, Rodrigo Vieira-Bernardo a,b, David Majerowicz ${ }^{a}$, \\ Katia C. Gondim ${ }^{\mathrm{a}}$, Marcos André Vannier-Santos ${ }^{\mathrm{d}}$, Angela H. Lopes ${ }^{c}$, José Roberto Meyer-Fernandes ${ }^{\mathrm{a}, \mathrm{b}, *}$ \\ a Instituto de Bioquímica Médica, Universidade Federal do Rio de Janeiro, CCS, Bloco H, Cidade Universitária, Ilha do Fundão, 21941-590 Rio de Janeiro, RJ, Brazil

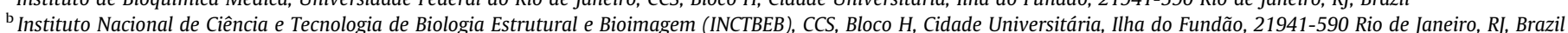 \\ ${ }^{\mathrm{c}}$ Instituto de Microbiologia Prof. Paulo de Góes, CCS, Universidade Federal do Rio de Janeiro, UFRJ, Cidade Universitária, Ilha do Fundão, CEP 21941-590, Rio de Janeiro, RJ, Brazil \\ d Centro de Pesquisas Gonçalo Muniz, Fundação Oswaldo Cruz (FIOCRUZ), Salvador, Bahia, Brazil
}

\section{A R T I C L E I N F O}

\section{Article history:}

Received 30 November 2010

Received in revised form 7 July 2011

Accepted 14 July 2011

Available online 30 July 2011

\section{Keywords:}

Ecto-3'-nucleotidase

Ecto-5'-nucleotidase

Leishmania amazonensis

Cellular adhesion

Adenosine

Ammonium tetrathiomolybdate

\begin{abstract}
A B S T R A C T
Ecto- $3^{\prime}$-nucleotidase/nuclease ( $\left.3^{\prime} \mathrm{NT} / \mathrm{NU}\right)$ is a membrane-bound enzyme that plays a key role in the nutrition of Leishmania sp. protozoan parasites. This enzyme generates nucleosides via hydrolyzes of 3'mononucleotides and nucleic acids, which enter the cell by specific transporters. In this work, we identify and

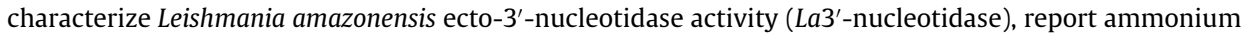
tetrathiomolybdate (TTM) as a novel $L a 3^{\prime}$-nucleotidase inhibitor and approach the possible involvement

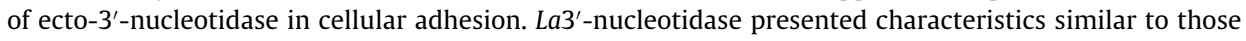
reported for the class I single-strand nuclease family; a molecular weight of approximately $40 \mathrm{kDa}$ and optimum activity in an alkaline $\mathrm{pH}$ range were observed. Although it is conserved among the genus, La3'-nucleotidase displays different kinetic properties; it can be inhibited by vanadate, molybdate and $\mathrm{Cu}^{2+}$ ions. Interestingly, ecto-3'-nucleotidase activity is 60-fold higher than that of ecto-5'-nucleotidase in L. amazonensis. Additionally, ecto-3'-nucleotidase activity is two-fold higher in virulent L. amazonensis cells than in avirulent ones. Notably, macrophage-parasite attachment/invasion was increased by $400 \%$ in the presence of adenosine 3'-monophosphate (3'AMP); however, this effect was reverted by TTM treatment. We believe that $L a 3^{\prime}$-nucleotidase may play a significant role in the generation of adenosine, which may contribute to mammalian host immune response impairment and establishment of infection.
\end{abstract}

(c) 2011 Elsevier Inc. All rights reserved.

\section{Introduction}

Leishmaniasis has two main clinical forms: cutaneous and visceral (Neuber, 2008). Leishmania amazonensis is prevalent in many regions of Brazil and induces muco-cutaneous lesions and diffuse cutaneous lesions upon infection (Grimaldi and Tesh, 1993). The parasite exists as a non-motile, spherical amastigote, which proliferates inside the phagolysosomes of macrophages found in vertebrate hosts (e.g., humans, dogs, cats and rodents) and as a flagellate promastigote that is transmitted during bits from sand fly vectors (Cunningham, 2002).

Adenosine, an endogenous purine nucleoside, is a biologically active molecule that is extracellularly formed at sites of metabolic stress associated with ischemia (anoxia/hypoxia), trauma or inflammation (Csóka et al., 2007). In mammals, adenosine plays

\footnotetext{
* Corresponding author at: Laboratório de Bioquímica Celular, Instituto de Bioquímica Médica, Centro de Ciências da Saúde, Universidade Federal do Rio de Janeiro, UFRJ, Cidade Universitária, Ilha do Fundão, 21941-590 Rio de Janeiro, RJ, Brazil. Fax: +55 2122708647.

E-mail address: meyer@bioqmed.ufrj.br (J.R. Meyer-Fernandes).
}

an essential role in regulating the innate and acquired immune responses. Adenosine acts by engaging P1 $\left(A_{1}, A_{2 A}, A_{2 B}\right.$ and $\left.A_{3}\right)$ receptors, expressed on neutrophils, macrophages (Haskó et al., 2009), dendritic cells (Ben Addi et al., 2008) and T lymphocytes (Gessi et al., 2007).

It has been demonstrated that several pathogens present an enzymatic adenosine-generating apparatus to escape the host immune response (Tasca et al., 2003, 2005; Borges et al., 2007; Marques-da-Silva et al., 2008; Pettengill et al., 2009; Thammavongsa et al., 2009; Kiffer-Moreira et al., 2010; Russo-Abrahão et al., 2011a,b). Trypanosomatids are incapable of synthesizing adenosine de novo; however, this nucleoside can be generated by ecto-nucleotidases via the sequential hydrolyzes of extracellular adenosine triphosphate (ATP) (Fonseca et al., 2006; Leite et al., 2007; Meyer-Fernandes et al., 2010). Our group has previously demonstrated that $L$. amazonensis possesses all of the enzymes that participate in sequential ATP hydrolysis (Berredo-Pinho et al., 2001; Pinheiro et al., 2006; Peres-Sampaio et al., 2008; de Souza et al., 2011). Parasites of the genus Leishmania, also present a fully active enzyme termed, 3'-nucleotidase/nuclease capable of hydrolyzing $3^{\prime}$-mononucleotides to nucleosides, as well as the nucleic acids in 
5'-mononucleotides, located solely at the plasma membrane (Gottlieb and Dwyer, 1983; Dwyer and Gottlieb, 1984; Hassan and Coombs, 1987; Debrabant et al., 1995). Adenosine 3'-monophosphate ( $\left.3^{\prime} \mathrm{AMP}\right)$ is found in several mammalian tissues, especially in the spleen (Bushfield et al., 1990), which is a target organ in the potentially fatal visceral form of leishmaniasis.

As mentioned, 3'-nucleotidase/nucleases can generate adenosine and $5^{\prime}$-mononucleotides, which act as substrates for $5^{\prime}$-mononucleotidases (Gottlieb, 1985). Because adenosine has been reported to serve a significant role in immune modulation (Marques-da-Silva et al., 2008; de Souza et al., 2010), we believe that 3'-nucleotidase/ nuclease may also be implicated in host immune regulation. In this present work, we identify and characterize La3'-nucleotidase activity and discuss the possible roles of this enzyme in parasitehost interaction and infection.

\section{Materials and methods}

\subsection{Materials}

All reagents were purchased from E. Merck (São Paulo, Brazil) or Sigma-Aldrich (Sigma Co., St. Louis, MO). Deionized, distilled water was obtained from a MilliQ system of resins (Millipore Corp., Bedford, MA) and was used in the preparation of all solutions, including substrates and inhibitors.

\subsection{Cell culture}

The MHOM/BR/75/Josefa strain of $L$. amazonensis was used throughout this study. It was isolated from a human case of diffuse cutaneous leishmaniasis in Brazil by Dr. Cuba-Cuba (Universidade de Brasília, Brazil) and has been maintained within our laboratory in axenic culture as well as by hamster footpad inoculation. Promastigotes, cultured for long periods in axenic medium, are termed avirulent as they are unable to establish disease in experimental models. Freshly transformed virulent promastigotes were obtained from culturing amastigotes isolated from hamster lesions, and they were subcultured for up to five times. Both promastigote populations were cultured in Warren's medium, supplemented with $10 \%$ (vol/vol) heat-inactivated fetal bovine serum at $22{ }^{\circ} \mathrm{C}$, and were then harvested at the stationary phase of growth (five days after inoculation) by centrifugation, washed twice, and kept in $116.0 \mathrm{mM} \mathrm{NaCl}, 5.4 \mathrm{mM} \mathrm{KCl}, 5.5 \mathrm{mM}$ D-glucose and $50.0 \mathrm{mM}$ HEPES buffer ( $\mathrm{pH} 7.4$ ).

Cellular viability was assessed, before and after incubations, by Trypan blue dye exclusion (Pinheiro et al., 2007) or by colorimetric assay using the oxidation-reduction indicator Alamar Blue (Mikus and Steverding, 2000).

\subsection{3'-nucleotidase activity measurements}

The 3'-nucleotidase activity was measured by the rate of phosphate release by the $3^{\prime} \mathrm{AMP}$ hydrolysis. Intact promastigotes $\left(1 \times 10^{7}\right.$ cells $\left.\mathrm{mL}^{-1}\right)$ were incubated for $1 \mathrm{~h}$ at $25^{\circ} \mathrm{C}$ in a $0.5 \mathrm{~mL}$ reaction mixture containing $116.0 \mathrm{mM} \mathrm{NaCl}, 5.4 \mathrm{mM} \mathrm{KCl}, 5.5 \mathrm{mM}$ glucose, $50.0 \mathrm{mM}$ HEPES-Tris buffer ( $\mathrm{pH} 7.4$ ) and 5.0 mM 3'AMP. The reaction was initiated by the addition of cells and stopped by the addition of $1.0 \mathrm{~mL}$ of ice-cold $25 \%$ charcoal in $0.1 \mathrm{M} \mathrm{HCl}$. This charcoal suspension was washed at least 20 times with $0.1 \mathrm{M}$ $\mathrm{HCl}$ before use to avoid Pi contamination (Russo-Abrahão et al., 2011a). This procedure reduces the values of blanks and removes non-hydrolyzed 3'AMP from the sample that is spontaneously hydrolyzed in the presence of the sulfuric acid in the Fiske-Subbarow reactive mixture (Fiske and Subbarow, 1925). Controls in which cells were added after interruption of the reaction were used as blanks. After the reaction, the tubes were centrifuged at $1500 \mathrm{~g}$ for $15 \mathrm{~min}$ at $4^{\circ} \mathrm{C}$, and $0.5 \mathrm{~mL}$ of the clear supernatant was added to $0.5 \mathrm{~mL}$ of Fiske-Subbarow reactive mixture (Fiske and Subbarow, 1925). The ecto-3'-nucleotidase activity was calculated by subtracting the nonspecific 3'AMP hydrolysis measured in the absence of cells. The concentration of Pi released in the reaction was determined using a standard curve of Pi for comparison.

In the experiments where divalent cations such as, $\mathrm{Mn}^{2+}, \mathrm{Ca}^{2+}$ $\mathrm{Sr}^{2+}, \mathrm{Cd}^{2+}, \mathrm{Cu}^{2+}, \mathrm{Fe}^{2+}$ and $\mathrm{Fe}^{3+}$ were tested, the possible formation of precipitates was investigated as described previously (Meyer-Fernandes and Vieyra, 1988). Under the conditions employed here, in a reaction medium containing $116 \mathrm{mM} \mathrm{NaCl}, 5.4 \mathrm{mM} \mathrm{KCl}, 5.5 \mathrm{mM}$ Dglucose, $50 \mathrm{mM}$ HEPES-Tris buffer, pH 7.2 and $5 \mathrm{mM}$ 3'AMP, no phosphate precipitates were observed in the presence of these cations.

\subsection{3'-nucleotidase gel activity assay}

The parasites were harvested by centrifugation, washed in a buffer solution containing $116 \mathrm{mM} \mathrm{NaCl}, 5.4 \mathrm{mM} \mathrm{KCl}, 5.5 \mathrm{mM}$ glucose and 50.0 mM HEPES-Tris buffer ( $\mathrm{pH} 7.4$ ) and suspended in lysis buffer (20 mM Tris-HCl buffer, pH 7.4, 1 mM EGTA, $1 \mathrm{mM}$ EDTA). The parasites were then freeze-thawed twice and homogenates were used for the assays. The protein concentration was determined (Lowry et al., 1951) using bovine serum albumin (BSA) as the standard. Aliquots of the parasitic extract ( $80 \mu \mathrm{g}$ protein) were separated by non-denaturing polyacrylamide gel electrophoresis (Laemmli, 1970). The enzyme activity was detected in situ by gel analysis. The gels were incubated for $30 \mathrm{~min}$ at $25^{\circ} \mathrm{C}$ in reaction mixtures containing $100 \mathrm{mM}$ Tris- $\mathrm{HCl}$ buffer ( $\mathrm{pH} 7.4$ ) and $5 \mathrm{mM} 3^{\prime}$-AMP, followed by Pi staining with a malachite green-molybic acid solution (Zlotnick et al., 1987).

\subsection{5'-nucleotidase activity measurements}

Ecto-5'-nucleotidase activity was assayed under the same experimental conditions used to determine ecto-3'-nucleotidase activity, except for the replacement of $3^{\prime}$ AMP for 5'AMP.

\subsection{3'-nucleotidase cDNA cloning e sequence analysis}

Total RNA was extracted from $1 \times 10^{7}$ parasites by TRIzol reagent (Invitrogen, Carlsbad, CA), according to manufacturer instructions. Total RNA samples were quantified with Nanodrop ND-1000 (Thermo Scientific, Wilmington, DE) and $1 \mu \mathrm{g}$ was treated with DNAse I (Fermentas, Ontario, Canada). After that, RNA was reverse transcribed to cDNA using High Capacity Reserve Transcriptase Kit (Applied Biosystem, Carlsbad, CA). L. amazonensis 3'nucleotidase cDNA was amplified by PCR reaction with cDNA samples as template and the following primers: $\mathrm{Lm} 3$ nucF $\left(5^{\prime}\right.$-ATG GCT CGA GCT CGT TTC CT-3') and Lm3nucR (5'-TTA CAG GGA TAC CGG CTC GT-3'). PCR product was cloned into pGEM-T Easy vector (Promega, Madison, WI) and the insert was sequenced in laboratório Sonda (Rio de Janeiro, Brazil). cDNA sequence is stored in GenBank under access number (JF792393).

L. amazonensis $3^{\prime}$-nucleotidase protein primary sequence was deduced from cDNA sequence and compared to other 3'-nucleotidase using BlastP algorithm (Altschul et al., 1997) with default parameters. Dendrogram tree was constructed with MEGA 4.0 software (Tamura et al., 2007), by Neighbor-Joining using 1000 replications bootstrap.

\subsection{Interaction assay}

Thioglycolate-elicited peritoneal macrophages from female $\mathrm{BALB} / \mathrm{c}$ mice were collected in $0.9 \%$ saline and were allowed to 
adhere to coverslips placed in 24-well culture plates for $30 \mathrm{~min}$ at $37{ }^{\circ} \mathrm{C}$ under a $4 \% \mathrm{CO}_{2}$ atmosphere. The non-adherent parasites cells were removed, and the monolayers were washed twice with $0.9 \%$ saline and cultured for $24 \mathrm{~h}$ in RPM-I 1640 medium pH 8.0, supplemented with $10 \%$ fetal bovine serum. The interaction assays were performed for $120 \mathrm{~min}$, as previously described (Vannier-Santos et al., 1995). A 10:1 parasite-to-macrophage ratio (about $10^{5}$ macrophages/coverslip) with $1 \mathrm{mM} 3^{\prime} \mathrm{AMP}, 1 \mathrm{mM}$ adenosine, $1 \mathrm{mM}$ $5^{\prime} \mathrm{AMP}$ and in the absence or presence of $100 \mu \mathrm{M}$ TTM was used. After conducting the interaction assays, the coverslips were fixed, and stained with Giemsa and the percentage of infected macrophages was determined by counting 600 cells in triplicate coverslips. The association indices were determined by multiplying the percentage of infected macrophages by the mean of the parasites per cell.

\subsection{Statistical analysis}

All experiments were performed in triplicate with at least three independent experiments. The values shown in all experiments represent the average \pm SE. Kinetic parameters, apparent $K_{\mathrm{m}}$ and $V_{\max }$ values were calculated using a nonlinear regression analysis of the data to the Michaelis-Menten equation. $K_{\mathrm{i}}$ value was calculated by the fit to the experimental data using the equation $v_{\mathrm{i}} /$ $v_{0}=K_{\mathrm{i}} /\left(K_{\mathrm{i}}+[\mathrm{TTM}]\right)$ where $v_{\mathrm{i}}$ and $v_{0}$ are the velocities of $3^{\prime} \mathrm{AMP}$ hydrolysis in the presence and absence of TTM, respectively. The data were analyzed statistically by means of Student's $t$-test or by ANOVA One Way followed by the Tukey test using the Prism computer software (Graphpad Software Inc., San Diego, CA, USA). $p$ values of 0.05 or less were considered significant.

\section{Results}

The time-course of ecto-3'-nucleotidase activity on the L. amazonensis surface was linear for $1 \mathrm{~h}$ and directly proportional to the number of parasites (data not shown). At a $\mathrm{pH} 7.4$, intact promastigotes were able to hydrolyze extracellular 3'AMP at a rate of

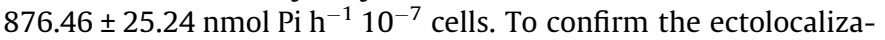
tion of L. amazonensis 3 'nucleotidase activity, ruling out the possibility that the observed 3'AMP hydrolysis was due to cytosolic enzymes, intact promastigotes and promastigote lysates were comparatively assayed for 3'-nucleotidase activity; no differences in the rate of 3'AMP hydrolysis were observed (Fig. 1A). These data confirmed that the $3^{\prime}$-nucleotidase activity is exclusively located on the $L$. amazonensis external surface. A non-denaturing activity gel was performed, and only one band could be visualized (Fig. 1B). The protein had a molecular mass of approximately $40 \mathrm{kDa}$, which is in accordance with the Leishmania mexicana 3 '-nucleotidase/ nuclease protein (Bates, 1993) and slightly lower than Leishmania donovani 3 '-nucleotidase/nuclease protein (43 kDa) (Campbell et al., 1991).

To verify the range of the optimum $\mathrm{pH}$ for La3'-nucleotidase activity, the enzyme activity was assayed at $\mathrm{pH}$ values ranging from 4.0 and 9.0 using MES-HEPES-Tris buffers. The enzyme exhibited increased activity in accordance with the alkalinization of the reaction medium, showing optimal activity at $\mathrm{pH} 9.0$ $\left(1.415 \pm 124 \mathrm{nmol} \mathrm{Pi} \mathrm{h}^{-1} 10^{-7}\right.$ cells) (Fig. 2). The assay was performed in the presence of levamizole, a specific alkaline phosphatase inhibitor (Van Belle, 1976), at pH 9.0 (open circle) to exclude the participation of an alkaline phosphatase in the hydrolysis of the 3'AMP; no significant differences were observed, comparing the activities with or without this inhibitor. At physiological $\mathrm{pH}$ range ( $\mathrm{pH} 7.0-7.4$ ), the $L a 3^{\prime}$-nucleotidase activity was $58 \%$ of that measured at $\mathrm{pH} 9.0$.

The $L a 3^{\prime}$-nucleotidase activity was also assayed at $\mathrm{pH} 7.4$ and in the presence of sodium fluoride $(\mathrm{NaF})$, tartarate, levamizole, vanadate and ammonium molybdate. Interestingly, $1 \mathrm{mM}$ vanadate and $1 \mathrm{mM}$ ammonium molybdate were able to inhibit La3'-nucleotidase activity by $30 \%$ and $40 \%$, respectively (Fig. 3 ). Although vanadate has been described as a phosphatase inhibitor (de AlmeidaAmaral et al., 2006), this enzyme was not involved in the 3'AMP hydrolysis once that in the non-denaturing polyacrylamide gel activity only one band was observed (Fig. 1B).

The dependence on 3'AMP concentration shows normal Michaelis-Menten kinetics for the $\mathrm{La}^{\prime}$ '-nucleotidase activity and the values of $V_{\max }$ and apparent $K_{\mathrm{m}}$ for $3^{\prime} \mathrm{AMP}$ were $923.71 \pm 23.54 \mathrm{nmol} \mathrm{Pi}$ $\mathrm{h}^{-1} 10^{-7}$ cells and $0.088 \pm 0.012 \mathrm{mM}$, respectively (Fig. 4 ). The apparent $K_{\mathrm{m}}$ value of $L a 3^{\prime}$-nucleotidase activity for $3^{\prime}$ AMP is very similar with $K_{\mathrm{m}}$ values found for 3'nucleotidase from $L$. donovani (Gbenle and Dwyer, 1992). Furthermore, we verified the modulation of the $L a 3^{\prime}$-nucleotidase activity by the addition of metals and metal-chelating agents (EDTA and EGTA). As shown in Fig. 5, $\mathrm{Cd}^{2+}$ and $\mathrm{Cu}^{2+}$ ions were able to inhibit the activity of this enzyme. Notably, $\mathrm{Cu}^{2+}$ ions almost completely abolished La $^{\prime}$-nucleotidase activity, inhibiting 3'AMP hydrolysis by $95 \%$. This data may be indicating that possible $\mathrm{Cu}$-enzyme derivates formation could be influenced enzyme catalytic activity (Zheng et al., 2003).

After partial biochemical characterization of La3'-nucleotidase activity and confirmation that the enzyme presents high capacity for hydrolyzing 3'AMP, releasing phosphate and adenosine, we attempted to verify the La3'-nucleotidase activity in infective promastigotes. Notably, virulent $L$. amazonensis promastigotes display a two-fold higher activity than avirulent promastigotes (maintained in axenic culture for over 100 passages) (Fig. 6A). This result led us to hypothesize that adenosine-supply accomplished by this enzyme could take part in a parasite-mammalian host cell interac-
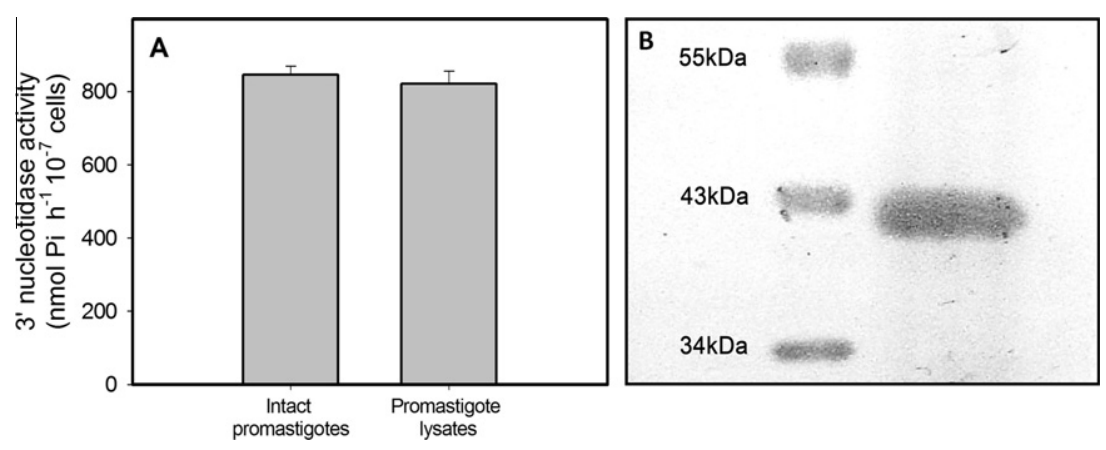

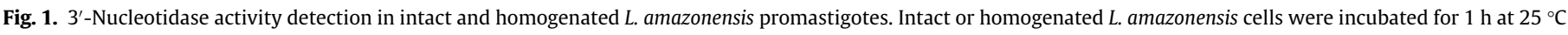

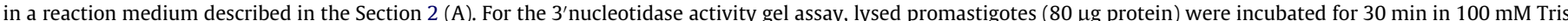

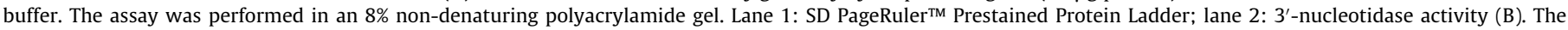
values represent the means \pm standard errors of at least three independent experiments performed in triplicate. 


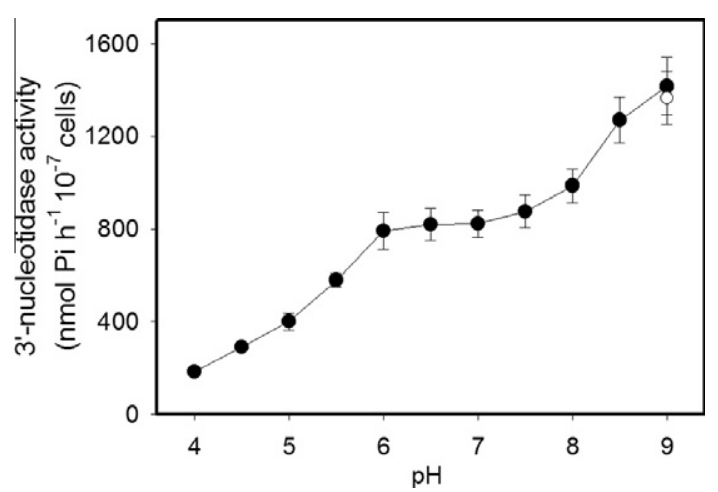

Fig. 2. Effect of $\mathrm{pH}$ on $\mathrm{La3}^{\prime}$-nucleotidase activity. Intact parasites were assayed as described in Section 2 at $\mathrm{pH}$ values raging from 4.0 to 9.0 (closed circle), using $50 \mathrm{mM}$ MES-HEPES-Tris buffer ( $50 \mathrm{mM}$ for each buffer). The reaction was started by addition of living intact promastigotes cells. As a control, cells were assayed at $\mathrm{pH} 9.0$ in the presence of $1.0 \mathrm{mM}$ levamizole (open circles). The values represent the means \pm standard errors of at least three independent experiments performed in triplicate.

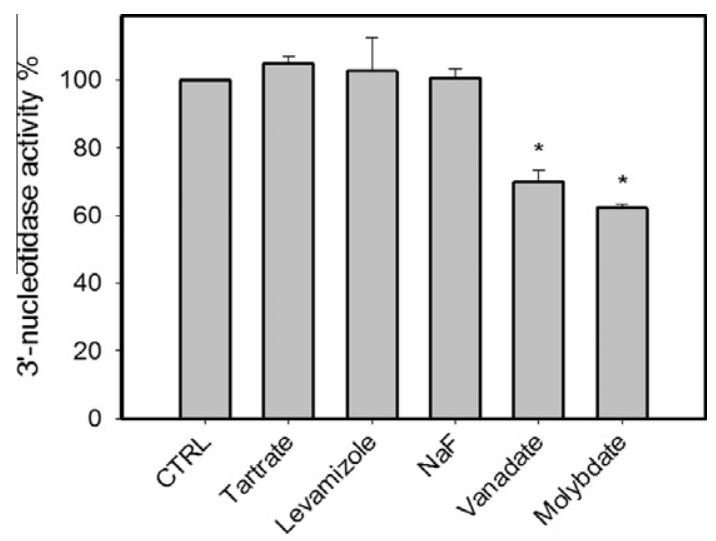

Fig. 3. Effect of phosphatase inhibitors on La $^{\prime}$-nucleotidase activity. Intact parasites were assayed as described in Section 2 in the presence of $1 \mathrm{mM}$ tartrate; $1 \mathrm{mM}$ levamizole; $1 \mathrm{mM}$ NaF; $1 \mathrm{mM}$ vanadate and $1 \mathrm{mM}$ molybdate. The reaction was started by the addition of living intact promastigote cells. 876.46 \pm $25.24 \mathrm{nmol} \mathrm{Pi} \mathrm{h}{ }^{-1} 10^{-7}$ cells for $3^{\prime}$-nucleotidase activity was taken to be $100 \%$ and the standard errors were calculated from the absolute activity values of three experiments using cell suspensions and converted to the percentage of the control value. *Denotes a statistically significant difference $(p<0.05)$ in comparison with the control (no addition).

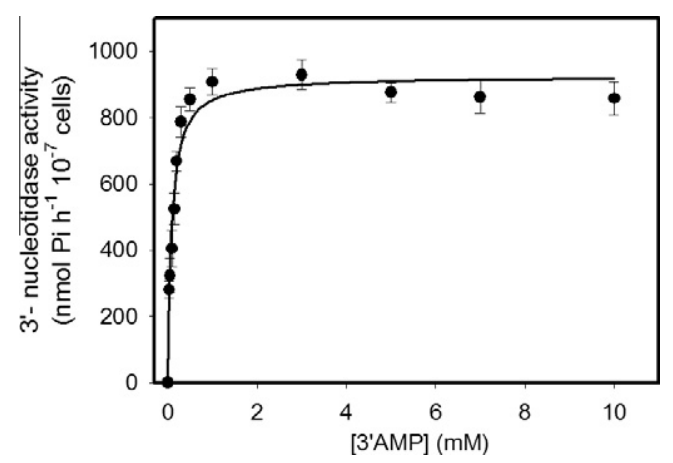

Fig. 4. Dependence on 3'AMP concentration on the La3'-nucleotidase activity. Promastigotes were incubated in the reaction medium as described in Section 2, supplemented with varying concentrations of 3'AMP. The ecto-3'nucleotidase activity was measured at different periods of time, and 3'AMP hydrolysis did not exceed $10 \%$. The curve represents the fit of the experimental data by nonlinear regression using the Michaelis-Menten equation. The data are expressed as the mean \pm SE of at least three experiments with different cell suspensions.

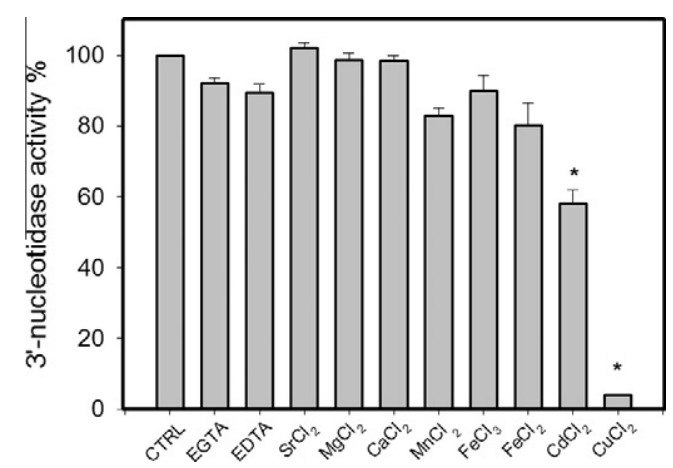

Fig. 5. Effect of divalent and trivalent metals on La3'-nucleotidase activity. Intact parasites were assayed as described in Section 2, in the presence of $1 \mathrm{mM}$ (EDTA, EGTA, $\mathrm{FeCl}_{2}, \mathrm{FeCl}_{3}$ and $\left.\mathrm{CuCl}_{2}\right)$ and $5 \mathrm{mM}\left(\mathrm{SrCl}_{2}, \mathrm{MgCl}_{2}, \mathrm{CaCl}_{2}, \mathrm{MnCl}_{2}\right.$ and $\left.\mathrm{CdCl}_{2}\right)$. It was not possible to study the influence of concentrations of $\mathrm{FeCl}_{2}, \mathrm{FeCl}_{3}$ and $\mathrm{CuCl}_{2}$ above $1 \mathrm{mM}$, once that phosphate precipitates were observed. The reaction was started by the addition of living intact promastigotes cells. 876.46 \pm $25.24 \mathrm{nmol} \mathrm{Pi} \mathrm{h}{ }^{-1} 10^{-7}$ cells for $3^{\prime}$-nucleotidase activity was taken to be $100 \%$ and the standard errors were calculated from the absolute activity values of three experiments with cells suspensions and converted to percentage of the control value. *Denotes a statistically significant difference $(p<0.05)$ in comparison with the control (no addition).

tion. When the $3^{\prime}$-nucleotidase activity was compared to the $5^{\prime}$ nucleotidase activity, a 60-fold difference was observed (Fig. 6B). In an interaction assay, $100 \mu \mathrm{M} 3^{\prime}$ AMP contributed significantly to L. amazonensis-macrophage interaction, while $1 \mathrm{mM} 5^{\prime} \mathrm{AMP}$ significantly increased the parasite attachment. Interestingly, the increased promastigote adhesion in the presence of $500 \mu \mathrm{M}$ and $1 \mathrm{mM}$ 3'AMP was comparable to the interaction observed in the presence of the same concentration of adenosine (Fig. 6C). Moreover, the other product of $3^{\prime}$ AMP hydrolysis, inorganic phosphate (Pi) did not increase macrophage infection. These data suggest that the high capability of 3'-nucleotidase to hydrolyze 3'AMP, and consequently generate adenosine, could contribute to parasite-host interactions.

It was demonstrated that L. donovani and Crithidia luciliae $3^{\prime}$ nucleotidase activities are inhibited by reducing agents that contain thiol groups (Neubert and Gottlieb, 1990; Gbenle and Dwyer, 1992). The sensitivity of $L a 3^{\prime}$-nucleotidase activity to ammonium molybdate reported in the present work (Fig. 3) led us to study another molybdate analog, ammonium tetrathiomolybdate (TTM). This compound inhibits $L a 3^{\prime}$-nucleotidase activity in a dose-dependent manner (Fig. 7), with an $K_{\mathrm{i}}$ of $5 \mu \mathrm{M}$. Parasites viability was not altered when pre-incubated with $100 \mu \mathrm{M}$ TTM for $2 \mathrm{~h}$ as determined by Trypan blue dye exclusion or by the oxidation-reduction indicator Alamar Blue (data not shown).

In order to further understand the possible role of $3^{\prime}$-nucleotidase activity in parasite-macrophage interactions, an assay was performed in the presence of $100 \mu \mathrm{M}$ TTM (Fig. 8). TTM was able to completely prevent the increased parasite-macrophage interactions promoted by $3^{\prime}$ AMP, corroborating the $3^{\prime}$-nucleotidase activity inhibition data conducted in the presence of these compounds (Fig. 7). These results suggest that TTM can completely prevent the generation of adenosine by 3 '-nucleotidase as well as the action of adenosine in promoting parasite-macrophage interactions.

A cDNA sequence with high homology to $3^{\prime}$-nucleotidase/nuclease from other trypanosomatids was cloned and sequenced. La $^{\prime}$ nucleotidase/nuclease amino acid sequence deduced from cDNA sequence predicted a protein with molecular weight of $41.7 \mathrm{kDa}$, in accordance to band size observed on activity gel (Fig. 1B). BlastP algorithm analysis indicated that 3'-nucleotidase/nuclease is high conserved through trypanosomatids evolution, showing identity values raging from $65 \%$ to $99 \%$ (Table 1). L. amazonensis protein dif- 

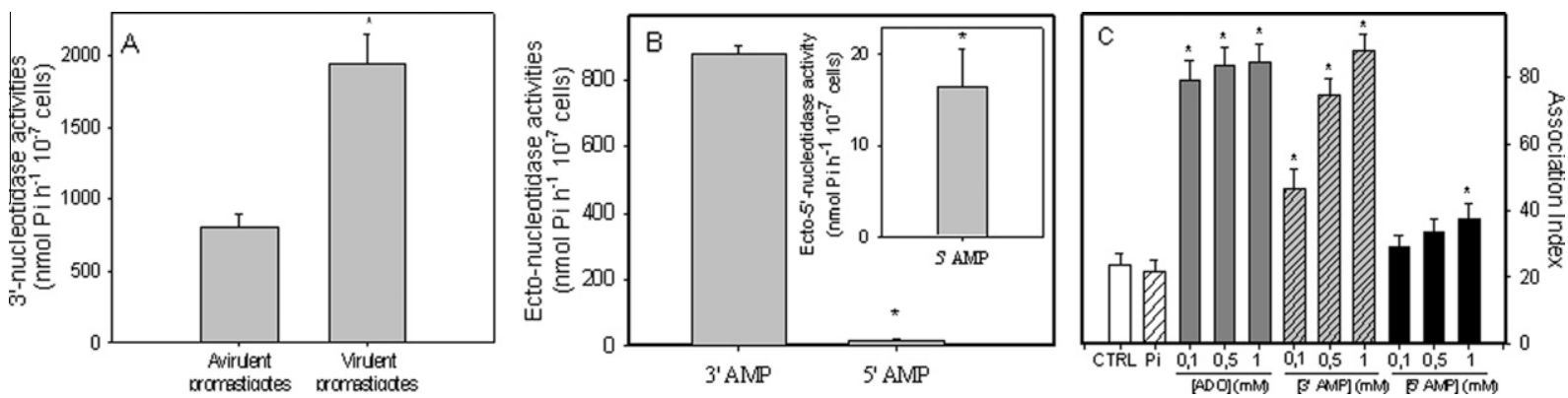

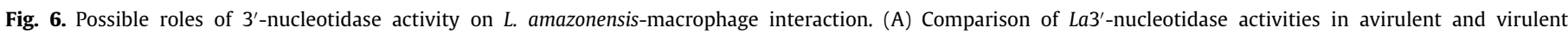

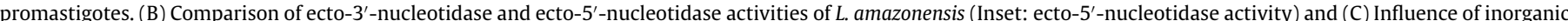

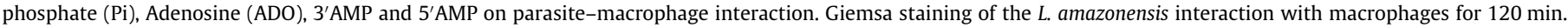

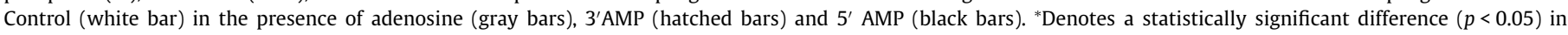
comparison to the control (no addition).

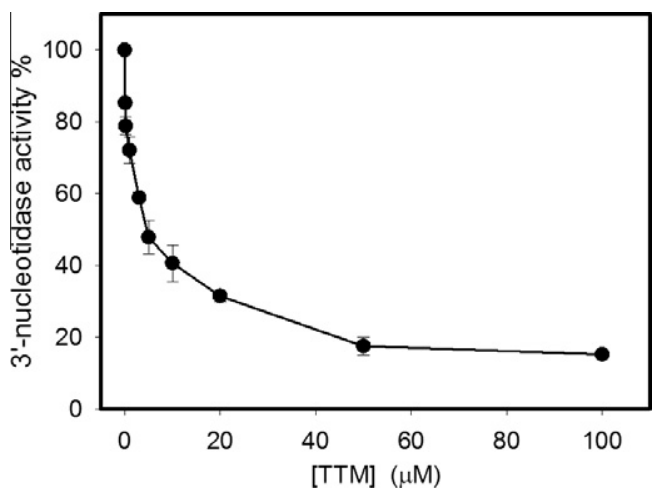

Fig. 7. Effect of ammonium tetrathiomolybdate (TTM) on La3'-nucleotidase activity. Intact parasites were assay as described in Section 2 in the presence of several concentrations of TTM. The reaction was started by the addition of living intact promastigotes cells. $876.46 \pm 25.24 \mathrm{nmol} \mathrm{Pi} \mathrm{h}{ }^{-1} 10^{-7}$ cells for $3^{\prime}$-nucleotidase activity in the absence of TTM was taken to be $100 \%$.

fer from L. mexicana homologue by only four amino acids (data not shown). Dendrogram tree constructed using different nucleases from Leishmania already described showed that La3'-nucleotidase/nuclease get grouped with all other $3^{\prime}$-nucleotidase/nuclease from Leishmania genus in one separated branch (Fig. 9).

\section{Discussion}

In this work, we characterized La3'-nucleotidase activity in $L$. amazonensis and for the first time, we propose its involvement in
Table 1

Comparison between amino acid sequences of 3'-nucleotidase from Leishmania amazonensis and other trypanosomatids.

\begin{tabular}{llll}
\hline Access number $^{\mathrm{a}}$ & Organism & ${\text { Identity }(\%)^{\mathrm{b}}}$ & ${\text { Similarity }(\%)^{\mathrm{b}}}^{\mathrm{b}}$ \\
\hline CAC17409 & Leishmania mexicana & 99 & 99 \\
XP_001467555 & Leishmania infantum & 88 & 93 \\
AAC41574 & Leishmania donovani & 88 & 93 \\
XP_001685218 & Leishmania major & 87 & 94 \\
XP_001567250 & Leishmania braziliensis & 72 & 85 \\
AAF66482 & Crithidia luciliae & 65 & 79 \\
\hline
\end{tabular}

a Access number from GenBank database.

b Identity and similarity were calculated with BlastP algorithm.

macrophage-parasite attachment, the earliest event in host cell infection (Vannier-Santos et al., 1995; Cunningham, 2002). We used intact parasites in our model study to be certain that the observed $3^{\prime}$-nucleotidase activity responsible for the hydrolysis of 3'AMP would be generated from a genuine, ecto-3'-nucleotidase. This was confirmed by the activity gel assay, which demonstrated only one band with a molecular mass of approximately $40 \mathrm{kDa}$ and that phosphatase inhibitors such as NaF, levamizole, or tartrate (Dutra et al., 2001; Dick et al., 2010) failed to inhibit 3'AMP hydrolysis. Several works have demonstrated that a number of Leishmania sp. present an amino acid sequence in the 3 '-nucleotidase catalytic site identical to that of the catalytic site of the P1 nuclease (Debrabant et al., 1995; Sopwith et al., 2002; Farajnia et al., 2004; Lakhal-Naouar et al., 2008). Accordingly, the inhibition observed in the presence of $\mathrm{Cu}^{2+}$ ions, could be indicating the formation of $\mathrm{Cu}$ enzyme derivates that influenced enzyme catalytic activity
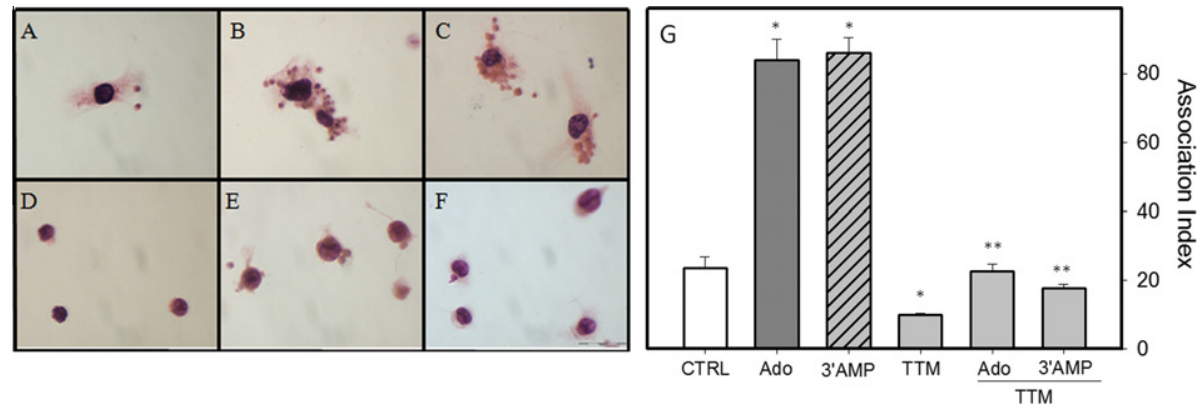

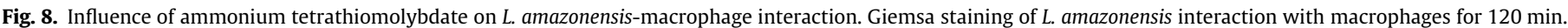

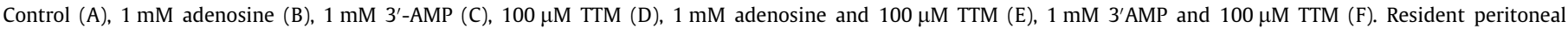

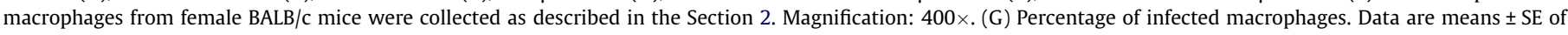

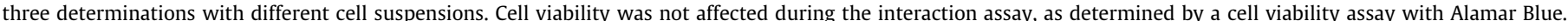

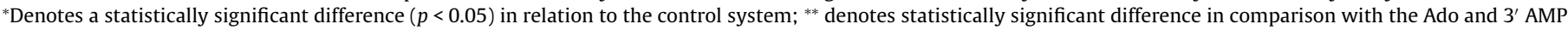
group without TTM. 


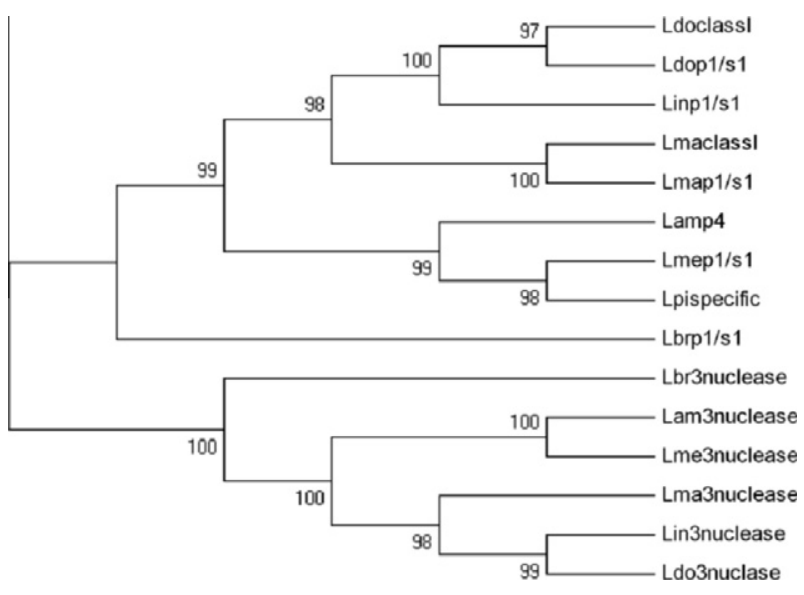

Fig. 9. Dendrogram tree of nucleotidase/nuclease from Leishmania genus. Amino acid sequence from Leishmania nucleotidase/nuclease were aligned by Clustal algorithm and dendrogram tree was constructed using MEGA 4.0, by NeighborJoining method and 1000 replications of bootstrap. The numbers indicate bootstrap values for each branch. Ldo: $L$. donovani; Lin: L. infantum; Lma: L. major; Lam: $L$. amazonensis; Lme: L. mexicana, Lpi: L. pifanoi; Lbr: L. braziliensis.

(Zheng et al., 2003). La3'-nucleotidase activity also presented kinetic and biochemical properties similar to those described for the 3'-nucleotidases of others trypanosomatides, such as L. donovani (Gbenle and Dwyer, 1992), Leishmania chagasi (Vieira et al., 2011) and C. luciliae (Neubert and Gottlieb, 1990).

The 3'-nucleotidase activity in virulent $L$. amazonensis promastigotes was two-fold higher than in avirulent promastigotes. This result is consistent with some reports that have demonstrated higher ecto-nucleotidase activities in infectious promastigotes compared to those maintained in culture medium (Berredo-Pinho et al., 2001; de Souza et al., 2010). It was proposed that such enzymes that participate in the sequential hydrolysis of ATP to adenosine contribute to the host immune balance response and favor infection establishment (de Souza et al., 2010; Meyer-Fernandes et al., 2010). However, the high activity of $L a 3^{\prime}$-nucleotidase is compared to those of Laecto- $5^{\prime}$-nucleotidase and ecto-ATPase in these works (Berredo-Pinho et al., 2001), and may suggest the participation of $L a 3^{\prime}$-nucleotidase in the generation of adenosine, not only for parasite metabolic demand, but also to regulate the immune response in the initial step of infection. The ecto-3'nucleotidase present on the surface of $L$. amazonensis, active within a range of physiological $\mathrm{pH}$ ( $\mathrm{pH} 7.0-7.4)$, may have physiological role in the generation of adenosine. Our parasite-macrophage interaction data clearly demonstrated the significance of 3'-nucleotidase-mediated adenosine generation in the establishment of intracellular parasitism. An increased interaction was observed in the presence of $1 \mathrm{mM} 3^{\prime}$ AMP, comparable to studies conducted in the presence of $1 \mathrm{mM}$ adenosine, indicating that $3^{\prime}$-nucleotidase may generate adenosine nucleosides. In this context, we believe that 3'-nucleotidase activity may generate adenosine at the site of infection, as well as contribute to the survival of the parasite by suppressing the innate host immune response.

In the present work, we also discovered TTM as a novel inhibitor of 3'-nucleotidase activity. TTM is a potent copper-chelating agent, and several reports have demonstrated its effect as an anti-tumor proliferation agent (Khan and Merajver, 2009). The inhibitory effect of $3^{\prime}$-nucleotidase activity is not due to copper chelation as the enzyme is not copper-dependent, not presenting this metal as prosthetic group. The data presented here, could help us study the possible role of this enzyme in parasite-macrophage interactions. TTM was able to completely prevent the increased interaction in the presence of 3'AMP, corroborating our enzyme activity assay and TTM inhibition. Additionally, TTM could possibly inhibit the interaction by another mechanism that is not involved with enzyme activity, as seen in our interaction assays in the absence of 3'AMP.

Structural characteristics of the deduced protein suggest that the L. amazonensis sequence described here is the functional equivalent of the L. donovani and L. mexicana genes (Debrabant et al., 1995; Sopwith et al., 2002). Further, our results demonstrated that the deduced protein from the $L a 3^{\prime}$-nucleotidase gene reported possesses conserved signature sequences characteristic of the class I nuclease gene family (Debrabant et al., 1995; Lakhal-Naouar et al., 2008; Sopwith et al., 2002). In this context, the $3^{\prime}$-nucleotidase would be a significant source of adenosine and would contribute to the establishment of infection by its potent immunosuppressive activity during the initial stages of Leishmania infection.

\section{Acknowledgments}

We would like to thank Mr. Fabiano Ferreira Esteves and Ms. Rosangela Rosa de Araújo for their excellent technical assistance. This work was supported by grants from the Brazilians Agencies Conselho Nacional de Desenvolvimento Científico e Tecnológico (CNPq), Coordenação de Aperfeiçoamento de Pessoal de Nível Superior (CAPES) and Fundação de Amparo à Pesquisa do Estado do Rio de Janeiro (FAPERJ).

\section{References}

Altschul, S.F., Madden, T.L., Schäffer, A.A., Zhang, J., Zhang, Z., Miller, W., Lipman, D.J., 1997. Gapped BLAST and PSI-BLAST: a new generation of protein database search programs. Nucleic Acids Research 25, 3389-3402.

Bates, P.A., 1993. Characterization of developmentally-regulated nucleases in promastigotes and amastigotes of Leishmania mexicana. FEMS Microbiology Letters 107, 53-58.

Ben Addi, A., Lefort, A., Hua, X., Libert, F., Communi, D., Ledent, D., Macours, P., Tilley S.L., Boeynaems, J.M., Robaye, B., 2008. Modulation of murine dendritic cell function by adenine nucleotides and adenosine: Involvement of the A2B receptor. European Journal of Immunology 38, 1610-1620.

Berredo-Pinho, M., Peres-Sampaio, C.E., Chrispim, P.P., Belmont-Firpo, R., Lemos A.P., Martiny, A., Vannier-Santos, M.A., Meyer-Fernandes, J.R., 2001. A Mgdependent ecto-ATPase in Leishmania amazonensis and its possible role in adenosine acquisition and virulence. Archives of Biochemistry and Biophysics 391, 16-24.

Borges, F.P., Gottardi, B., Stuepp, C., Larré, A.B., Tasca, T., De Carli, G.A., Bonan, C.D. 2007. Characterization of an ecto-5nucleotidase (EC 3.1.3.5) activity in intact trophozoites of Trichomonas gallinae. Veterinary Parasitology 143, 106-111.

Bushfield, M., Shoshani, I., Johnson, R.A., 1990. Tissue levels, source, and regulation of 3'-AMP: an intracellular inhibitor of adenylyl cyclases. Molecular Pharmacology 38, 848-853.

Campbell, T.A., Zlotnick, G.W., Neubert, T.A., Sacci, J.B.Jr., Gottlieb, M., 1991. Purification and characterization of the $3^{\prime}$-nucleotidase/nuclease from promastigotes of Leishmania donovani. Molecular and Biochemical Parasitology 47, 109-117.

Csóka, B., Németh, Z.H., Selmeczy, Z., Koscsó, B., Pacher, P., Vizi, E.S., Deitch, E.A., Haskó, G., 2007. Role of $\mathrm{A}(2 \mathrm{~A})$ adenosine receptors in regulation of opsonized $E$. Coli-induced macrophage function. Purinergic Signalling 3, 447-452.

Cunningham, A.C., 2002. Parasitic adaptive mechanisms in infection by Leishmania. Experimental and Molecular Pathology 72, 132-141.

de Almeida-Amaral, E.E., Belmont-Firpo, R., Vannier-Santos, M.A., Meyer-Fernandes, J.R., 2006. Leishmania amazonensis: characterization of an ecto-phosphatase activity. Experimental Parasitology 114, 334-340.

de Souza, M.C., de Assis, E.A., Gomes, R.S., Marques-da-Silva, E.D., Melo, M.N., Fietto J.L., Afonso, L.C., 2010. The influence of ecto-nucleotidases on Leishmania amazonensis infection and immune response in C57B/6 mice. Acta Tropica 115, 262-269.

de Souza, V.L., Veras, P.S.T., Welby-Borges, M., Silva, T.M.C., Leite, B.R., Ferraro, R.B. Meyer-Fernandes, J.R., Barral, A., Costa, J.M.L., Freitas, L.A.R., 2011. Memórias do Instituto Oswaldo Cruz 106, 23-31.

Debrabant, A., Gottlieb, M., Dwyer, D.M., 1995. Isolation and characterization of the gene encoding the surface membrane 3 '-nucleotidase/nuclease of Leishmania donovani. Molecular and Biochemical Parasitology 71, 51-63.

Dick, C.F., Dos-Santos, A.L., Fonseca-de-Souza, A.L., Rocha-Ferreira, J., Meyer-Fernandes, J.R., 2010. Trypanosoma rangeli: differential expression of ecto-phosphatase activities in response to inorganic phosphate starvation. Experimental Parasitology 124, 386-393.

Dutra, P.M., Dias, F.A., Rodrigues, C.O., Romeiro, A., Attias, M., De Souza, W., Lopes, A.H., Meyer-Fernandes, J.R., 2001. Platelet-activating factor modulates a secreted phosphatase activity of the trypanosomatid parasite Herpetomonas muscarum muscarum. Current Microbiology 43, 288-292. 
Dwyer, D.M., Gottlieb, M., 1984. Surface membrane localization of $3^{\prime}$ - and 5 'nucleotidase activities in Leishmania donovani promastigotes. Molecular and Biochemical Parasitology 10, 139-150.

Farajnia, S., Alimohammadian, M.H., Reiner, N.E., Karimi, M., Ajdari, S., Mahboudi, F., 2004. Molecular characterization of a novel amastigote specific class I nuclease from Leishmania major. International Journal for Parasitology 34, 899-908.

Fiske, C.H., Subbarow, Y., 1925. The colorimetric determination of phosphorous. The Journal of Biological Chemistry 66, 375-400.

Fonseca, F.V., Fonseca de Souza, A.L., Mariano, A.C., Entringer, P.F., Gondim, K.C. Meyer-Fernandes, J.R., 2006. Trypanosoma rangeli: characterization of a Mg-dependent ecto ATP-diphosphohydrolase activity. Experimental Parasitology 112, 76-84.

Gbenle, G.O., Dwyer, D.M., 1992. Purification and properties of 3 '-nucleotidase of Leishmania donovani. The Biochemical Journal 285, 41-46.

Gessi, S., Varani, K., Merighi, S., Fogli, E., Sacchetto, V., Benini, A., Leung, E., Mac-Lennan, S., Borea, P.A., 2007. Adenosine and lymphocyte regulation. Purinergic Signalling 3 , 109-116.

Gottlieb, M., Dwyer, D.M., 1983. Evidence for distinct $5^{\prime}$ - and $3^{\prime}$-nucleotidase activities in the surface membrane fraction of Leishmania donovan promastigotes. Molecular and Biochemical Parasitology 7, 303-317.

Gottlieb, M., 1985. Enzyme regulation in a trypanosomatid: effect of purine starvation on levels of 3'-nucleotidase activity. Science 227, 72-74.

Grimaldi, G.Jr., Tesh, R.B., 1993. Leishmaniases of the New World: current concepts and implications for future research. Clinical Microbiology Reviews 6, 230-250.

Haskó, G., Csóka, B., Németh, Z.H., Vizi, E.S., Pacher, P., 2009. A $_{2 \mathrm{~B}}$ adenosine receptors in immunity and inflammation. Trends in Immunology 30, 263-270.

Hassan, H.F., Coombs, G.H., 1987. Phosphomonoesterases of Leishmania mexicana mexicana and other flagellates. Molecular and Biochemical Parasitology 23, 285-296.

Khan, G., Merajver, S., 2009. Copper chelation in cancer therapy using tetrathiomolybdate: an evolving paradigm. Expert Opinion on Investigational Drugs $18,541-548$.

Kiffer-Moreira, T., Fernandes Sampaio, M.E., Alviano, D.S., Axelband, F., Cesar, G.V., Cosentino-Gomes, D., Rodrigues, M.L., Nimrichter, L., Vieyra, A., Alviano, C.S Meyer-Fernandes, J.R., 2010. Biochemical characterization of an ecto-ATP diphosphohydrolase activity in Candida parapsilosis and its possible role in adenosine acquisition and pathogenesis. FEMS Yeast Research 10, 735-746.

Lakhal-Naouar, I., Achour-Chenik, Y.B., Boublik, Y., Meddeb, M., Aamouri, A., Fattoum, A., Louzir, H., Chenik, M., 2008. Identification and characterization of a new Leishmania major specific 3'nucleotidase/nuclease protein. Biochemica and Biophysical Research Communications 375, 54-58.

Laemmli, U.K., 1970. Cleavage of structural proteins during the assembly of the head of bacteriophage T4. Nature 227, 680-685.

Leite, M.S., Thomaz, R., Fonseca, F.V., Panizzutti, R., Vercesi, A.E., Meyer-Fernandes, J.R., 2007. Trypanosoma brucei brucei: biochemical characterization of ecto-nucleoside triphosphate diphosphohydrolase activities. Experimental Parasitology 115, 315-323.

Lowry, O.H., Rosenbrough, N.J., Farr, A.L., Randall, R.J., 1951. Protein measurement with the Folin phenol reagent. The Journal of Biological Chemistry 193, 265-275.

Marques-da-Silva, E.A., de Oliveira, J.C., Figueiredo, A.B., de Souza Lima Júnior, D. Carneiro, C.M., Rangel Fietto, J.L., Crocco Afonso, L.C., 2008. Extracellular nucleotide metabolism in Leishmania: influence of adenosine in the establishment of infection. Microbes and Infection 10, 850-857.

Meyer-Fernandes, J.R., Vieyra, A., 1988. Pyrophosphate formation from acetyl phosphate and orthophosphate: evidence for heterogeneous catalysis. Archives of Biochemistry and Biophysics 266, 132-141.

Meyer-Fernandes, J.R., Cosentino-Gomes, D., Vieira, D.P., Lopes, A.H., 2010. EctoNucleoside Triphosphate Diphosphohydrolase activities in Trypanosomatids: Possible roles in infection, virulence and purine recycling. The Open Parasitology Journal 4, 116-119.
Mikus, J., Steverding, D., 2000. A simple colorimetric method to screen drug cytotoxicity against Leishmania using the dye Alamar Blue. Parasitology International 48, 265-269.

Neuber, H., 2008. Leishmaniasis. Journal of the German Society of Dermatology 6, $754-765$.

Neubert, T.A., Gottlieb, M., 1990. An inducible 3'-nucleotidase/nuclease from the trypanosomatid Crithidia luciliae. The Journal of Biological Chemistry 265, $7236-7242$.

Peres-Sampaio, C.E., de Almeida-Amaral, E.E., Giarola, N.L., Meyer-Fernandes, J.R., 2008. Leishmania amazonensis: effects of heat shock on ecto-ATPase activity. Experimental Parasitology 119, 135-143.

Pettengill, M.A., Lam, V.W., Ojcius, D.M., 2009. The danger signal adenosine induces persistence of chlamydial infection through stimulation of A2b receptors. PloS One 4, e8299.

Pinheiro, A.A.D., Amazonas, J.N., Barros, F.D., De Menezes, L.F., Batista, E.J.O., Silva, E.F., De Souza, W., Meyer-Fernandes, J.R., 2007. Entamoeba histolytica: an ectophosphatase activity regulated by oxidation-reduction reactions. Experimental Parasitology 115, 352-358.

Pinheiro, C.M., Martins-Duarte, E.S., Ferraro, R.B., Fonseca de Souza, A.L., Gomes, M.T., Lopes, A.H., Vannier-Santos, M.A., Santos, A.L., Meyer-Fernandes, J.R., 2006. Leishmania amazonensis: Biological and biochemical characterization of ectonucleoside triphosphate diphosphohydrolase activities. Experimental Parasitology 114, 16-25.

Russo-Abrahão, T., Cosentino-Gomes, D., Daflon-Yunes, N., Meyer-Fernandes, J.R., 2011a. Giardia duodenalis: Biochemical characterization of an ecto-5'nucleotidase activity. Experimental Parasitology 127, 66-71.

Russo-Abrahão, T., Cosentino-Gomes, D., Gomes, M.T., Alviano, D.S., Alviano, C.S., Lopes, A.H., Meyer-Fernandes, J.R., 2011b. Biochemical properties of Candida parapsilosis ecto-5nucleotidase and the possible role of adenosine in macrophage interaction. FEMS Microbiology Letters 317, 34-42.

Sopwith, W.F., Debrabant, A., Yamage, M., Dwyer, D.M., Bates, P.A., 2002. Developmentally regulated expression of a cell surface class I nuclease in Leishmania mexicana. International Journal for Parasitology 32, 449-459.

Tamura, K., Dudley, J., Nei, M., Kumar, S., 2007. MEGA4: Molecular evolutionary genetics analysis (MEGA) software version 4.0. Molecular Biology and Evolution 24, 1596-1599.

Tasca, T., Bonan, C.D., De Carli, G.A., Battastini, A.M.O., Sarkis, J.J.F., 2003. Characterization of an ecto-5́nucleotidase (EC 3.1.3.5) activity in intact cells of Trichomonas vaginalis. Experimental Parasitology 105, 167-173.

Tasca, T., Bonan, C.D., De Carli, G.A., Battastini, A.M.O., Sarkis, J.J.F., Alderete, J.F., 2005. Heterogeneity in extracellular nucleotide hydrolysis among clinical isolates of Trichomonas vaginalis. Parasitology 131, 71-78.

Thammavongsa, V., Kern, J.W., Missiakas, D.M., Schneewind, O., 2009 Staphylococcus aureus synthesizes adenosine to escape host immune responses. The Journal of Experimental Medicine 206, 2417-2427.

Vannier-Santos, M.A., Martiny, A., Meyer-Fernandes, J.R., de Souza, W., 1995. Leishmanial protein kinase $C$ modulates host cell infection via secreted acid phosphatase. European Journal of Cell Biology 67, 112-119.

Van Belle, H., 1976. Alkaline phosphatase. I. Kinetics and inhibition by levamisole of purified isoenzymes from humans. Clinical Chemistry 22, 972-976.

Vieira, D.P., Paletta-Silva, R., Saraiva, E.M., Lopes, A.H.C., Meyer-Fernandes, J.R., 2011. Leishmania chagasi: An ecto-3'nucleotidase activity modulated by inorganic phosphate and its possible involvement in parasite-macrophage interaction. Experimental Parasitology 127, 702-707.

Zheng, X.F., Wu, L., Gao, D.B., Chi, N.Y., Lin, Q.S., Hu, J.H., 2003. Applications of electron paramagnetic resonance spectroscopy to study interactions of metalloenzymes with Cu (II) ions. Spectrochimica Acta part A. 59, 1751-1755.

Zlotnick, G.W. Mackhow, M.C. Gottlieb, M. 1987. Renaturation of Leishmania donovani 3'-nucleotidase following sodium dodecyl sulfate-polyacrylamide gel electrophoresis. Comparative Biochemistry and Physiology. B, Comparative Biochemestry 87, 629-635. 